\title{
Chalámov e Dostoiévski: uma perspectiva sobre Recordações da Casa dos Mortos
}

\author{
Andrea Zeppini Menezes da Silva ${ }^{1}$
}

Resumo: O presente trabalho trata das experiências prisionais de Dostoiévski e Chalámov. Dostoiévski foi preso em 1849 e passou quatro anos em uma prisão de trabalhos forçados na Sibéria. Sobre esse período escreveu Recordações da Casa dos Mortos. Chalámov passou dezessete anos em campos de trabalho stalinistas, escrevendo depois Contos de Kolimá.

Palavras-Chave:Chalámov; Dostoiévski;testemunho

\begin{abstract}
This work deals with the prison experiences of Dostoevsky and Shalamov. Arrested in 1849, Dostoevsky spent four years in a forced labor prison in Siberia. About this period, he wrote Memoirs from the House of the Dead. Shalamov spent seventeen years in Stalinist labor camps, after that,wroteKolyma Tales, his main work.
\end{abstract}

Keywords: Shalamov; Dostoevsky; testimony

\section{Introdução}

Entre 1860 e 1861, Dostoiévski publicou Recordações da Casa dos Mortos, fruto de sua experiência em uma prisão de trabalhos forçados na Sibéria. Quasecem anos depois, em 1954, Chalámov começa a escrever seus Contos de Kolimá, sobre osdezessete anos passados em campos de trabalho do Gulag. As duas obras são um misto de memórias, documento, ficção. Memórias ficcionalizadas, memórias que encontraram suas formas artísticas. Literatura, enfim. A obra de Dostoiévski inaugura o gênero literário da prosa de prisão e a de Chalámov se insere nessa tradição, que se fez longa e farta na Rússia. Chalámovtoma a obra de memórias prisionais de Dostoiévski como referência, dialogando com ela, em geral para marcar a diferença de sua experiência e de sua literatura em relação ao romancista, que considerava gênio e profeta.

O presente trabalho tem o objetivo de indicar alguns pontos de contato, e de atrito, sobretudo, entre as obras desses dois escritores: o significado da experiência, o trabalho, a esperança, o contato com o mundo do crime presente nos campos e prisões, as grandes questões que estruturam seus textos.

\footnotetext{
${ }^{1}$ Doutoranda, Universidade de São Paulo-USP, bolsista CAPES, dedazeppini@ hotmail.com
} 


\section{Dostoiévski e Chalámov}

Dostoiévski foi preso em 1849, por conta de sua participação nas reuniões do circulo de Petrachévski, como eram chamadas as reuniões que aconteciam uma vez por semana no final da década de 40, na casa de Petrachévski, onde jovens discutiam assuntos proibidos pela censura pesada de Nicolau I, como a questão camponesa ou as revoluções na Europa. Condenado à morte, o escritor teve sua pena comutada para trabalhos forçados e exílio na Sibéria, em um lance teatral, quando estava prestes a ser executado. Passou quatro anos em uma prisão de trabalhos forçados e mais seis como soldado raso em uma cidadezinha siberiana, podendo retornar para a Rússia apenas no final da década de 50 .

Recordações da casa dos mortos trata desses quatro anos de prisão. Pode-se dizer que são memórias organizadas como esquetes, amarradas por uma moldura fictícia de dois narradores. Um deles é o editor do livro, que narra a introdução e apresenta Goriântchikov, o outro. Esse último é uma personagem que teria cumprido 10 anos de prisão por ter assassinado a esposae é o suposto narrador da obra, ainda que no decorrer do livro o escritor deixe pistas de que o narrador mesmo é o próprio Dostoiévski e não Goriântchikov. Especula-se que a moldura fictícia tenha sido criada como uma proteção à censura apenas e que o autor queria deixar claro quem era que estava falando. Voltando ao livro, ou melhor, à introdução do livro, o editor encontra entre os papeis de Goriântchikovas memórias do tempo de prisão e resolve publicá-las: tem início Recordações da Casa dos Mortos. Chalámov gostava muito dessa introdução, considerando-a fundamental para toda a obra do escritor que viria depois; também admirava a maneira sucinta e sarcástica como o narrador descreve a cidadezinha siberiana.

Ao contrário de Dostoiévski, Chalámov ainda não é conhecido aqui no Brasil. Por esse motivo, algumas palavras sobre ele, para situá-lo em seu contexto: nasceu em 1907, em Vologda e morreu em 1982, em Moscou, quase cem anos depois de Dostoiévski, morto em 1881. Filho de mãe professora e pai sacerdote da Igreja Ortodoxa, teve um irmão morto na frente de batalha durante a Guerra Civil. A família foi perseguida e ele só conseguiu ingressar na Faculdade de Direito de Moscou depois de entrar como operário em uma fábrica. Em 1927, já estudante, passa a fazer parte de um grupo de jovens trotskistas. Foi preso pela primeira vez em 1929, quando tentava 
imprimir e divulgar o chamado "testamento de Lênin" ou "carta ao congresso", texto de 1922 em que o líder bolchevique critica Stálin (TOKER. 2008). Recebe uma pena de três anos, cumprida em Solovki, um dos primeiros campos de trabalho, pertencente ao que viria a ser o extenso complexo de campos da União Soviética, denominado mais tarde como Gulag (Direção Geral dos Campos) e que, com o tempo, passou a designar "todo o sistema soviético de trabalho escravo em todas as suas formas e variedades: campos de trabalho, campos de castigo, campos para delinquentes comuns e para presos políticos, campos para mulheres, campos para crianças, campos de trânsito." (APPLEBAUM. 2006. P. 19). Solto em 1932, é preso novamente em 37, acusado de atividades antirrevolucionárias trotskistas. É mandado para Kolimá, condenado acinco anos em campos de trabalho.Na viagem para a "terra da morte branca", como Kolimá era chamada já nessa época (DOMÍNGUEZ. 2007), Chalámov passa por Omsk, cidade onde Dostoiévski cumprira sua pena quase um século antes. Mas Omsk ainda estava bem longe de Kolimá, em todos os sentidos.

Por dizer que Búnin era um clássico, Chalámov recebe mais uma pena, dessa vez de dez anos epermanece em Kolimá até 51, passando por minas de ouro e carvão, campos de castigo e de trânsito. Chega a ficar tão fraco que atinge o estado terminal e quase morre várias vezes, sendo salvo sempre pela sorte. Deixa Magadan, a "capital" de Kolimá, apenas em 53 e, reabilitado, pode retornar a Moscou em 1956.

\section{O testemunho, a escrita e a experiência}

Contos de Kolimáé o relato de dezessete anos de Gulag. São seis ciclos de contos, escritos entre 54 e 73, narrados sem dramaticidade ou enfeites. Apesar do grau de ficção, em seu texto "Sobre a Prosa"(1965), Chalámov diz que tudo o que está em sua obra é verdade, pois esta seria a marca que a experiência lhe deixou na alma: sua prosa "não é prosa de documento, mas prosa, que foi sofrida como documento"2. Escreveupara que as vítimas dos campos não fossem esquecidas: foi sua maneira de lutar contra o sistema, obrigação moral, ainda que lembrar fosse dolorido. Para o autor, sua prosa erauma bofetada contra o stalinismo (CHALÁMOV. 1971) e não haveria ali nada que não fosse o triunfo do bem e a superação do mal, ao menos no campo da arte.Como se o fato de lembrar, escrever e fazer lembrar superasse o mal sofrido, como

\footnotetext{
${ }^{2}$ Не проза документа, а проза, выстраданная как документ. (todas as traduções dos textos de Chalámov no presente trabalho são minhas)
} 
se operasse uma certa justiça o fato de transformar o mal em arte. Lembrar para poder esquecer.

Chalámov queria retratar a luta do homem contra o Estado, a luta por si mesmo e em si mesmo. Buscar o que resta de humano em homens vivendo sob condições subhumanas: existiria a possibilidade de algum grau de autonomia?Considerava sua obra uma novidade ainda que muito já tivesse sido escrito sobre os campos. A escrita aparentemente simples, sem rodeios, enfeites, adjetivos, fruto da experiência do autor; a verdade; a importância do sentimento, a importância do detalhe-símbolo como construtor de contextos, deixando para trás as longas descrições de paisagens e a construção de personagens dos realistas do XIX (CHALÁMOV. 1965). Essas eram as características do que chamou de "nova prosa", seu projeto literário.

Assim como Contos de Kolimá, Recordações da Casa dos Mortostambém foi escrito com o intuito de revelar o mundo dos trabalhos forçados. $\mathrm{E}$, diferente de Chalámov, cuja obra não fora publicada oficialmente em vida do autor dentro da Rússia,Dostoiévski publicou e conseguiu provocar na sociedade o debate que queria: entraram na pauta a justiça russa e o sistema prisional, os castigos corporais, a questão da flexibilidade das penas.Além disso, o livro devolvera a seu autor a notoriedade que ele conquistara rapidamente e rapidamente perdera, no início de sua carreira literária, nos anos 40 .

A obra tinha também o objetivo de veicular algumas mensagens. Dostoiévski queria, por exemplo,refutar a ideia de uma revolução: na convivência difícil com os outros detentos, camponeses, que receberam o escritor com muita hostilidade pelo fato dele ser um nobre, Dostoiévski descobriu que estes nunca aceitariam ser liderados por aristocratas em uma revoltacamponesa, como o próprio escritor chegou a sonhar na década de 40 e como sonhavam muitos membros da intelligentsia então. O episódio da "reclamação", em seu livro, é bem ilustrativo: certo dia, na prisão, os camponeses se unem para fazer uma reclamaçãopor conta da piora da comida.Sem saber direito o que acontecia, pensando tratar-se de uma chamada, Dostoiévskijunta-se a eles,que o expulsam dali: ele não era um deles.

Recordações da casa dos Mortos constrói literariamenteo processo de "regeneração" de Dostoiévski, apoiado, sobretudo,no seu encontro com o povo.Como observa Frank (1999. P. 139), quando foi preso, o escritor tinha uma concepção idealizada de povo, fruto de ideias filantrópicas e humanitárias dos anos 40 e de suas leituras dos romances sociais franceses da década de 30, de tendências socialistas e 
cristãs. Chegando à prisão, conviveu com o povo de verdade e ficou horrorizado. Para sua surpresa, a corrupção e a depravação não estavamsó com as classes mais altas: seus companheiros detentos bebiam, traficavam vodka, e roubavam uns dos outros sem o menor peso na consciência, além da prática da prostituição.

Mas a visão do escritor sobre o povo se transforma durante o relato, à medida em que o escritor se aproxima do povo e essa visão é idealizada de uma outra maneira, eis o processo de "regeneração". O episódio do teatro, por exemplo,é importantena aproximaçãodo escritor com o camponês:ao assistir uma representação organizada e encenada pelos detentos, Dostoiévski entra em contato com a cultura popular e percebe, surpreso,alta qualidade artística. E se comove com o prazer ingênuo com que os presos assistiam as apresentações. Também se impressiona com o cristianismo do povo.Em uma carta que escreve para o irmão logo que sai da prisão, é desse modo que Dostoiévski se refere ao povo:

Mesmo na cadeia, entre os bandidos, eu acabei por descobrir os homens ao longo desses quatro anos. Acredite: existem naturezas profundas, fortes, maravilhosas, e como é bom descobrir ouro sob uma casca rude. (...) Que povo maravilhoso. Em suma, não perdi meu tempo. Aprendi a conhecer, senão a Rússia, ao menos seu povo, a conhecê-lo bem, como talvez poucos o conheçam (DOSTOIÉVSKI. 2006. P. 324).

Dostoiévskipassa e verno camponês o portador dos valores russos, imagem que vai acompanhar o escritor pelo resto de sua vida e obra. Essa idealização, bem como o abandono das ideias socialistas fazem parte do que o escritor chamou de "regeneração". Esse processo faz com que se sinta, inclusive, grato pela experiência da prisão:

Só, com a minha alma, eu revia toda minha vida de antes, analisava-a até nos mínimos detalhes e condenava tudo quanto fizera no passado, transformando-me no meu próprio juiz severo e inquebrantável. Sim, houve muitas horas em que eu agradeci à minha sorte por haver me condenado àquela solidão, sem a qual não poderia julgar o meu passado nem decidir fiscalizar meus atos. E quantas esperanças não renasciam em meu coração! Eu dizia, eu jurava que na minha vida futura não cometeria outra vez os erros passados nem os antigos pecados. Organizava um programa para o futuro e prometia segui-lo fielmente. Nascia em mim uma fé cega de poder vir a realizar tudo isso! (DOSTOIÉVSKI. 2006. P. 297) 
Chalámov guarda uma impressão bem diferente dos detentos que encontra em Kolimá, além de sair do campo em um estado de espírito bem diferente. $\mathrm{Na}$ época desseescritor, os presos políticos eram tratados pela propaganda stalinista como “inimigos do povo"e os presos por crime comum eram usados pelas autoridades para controlar esses "inimigos". Discutindo com o autor de Crime e Castigo, Chalámov diz, em um de seus contos:

Em Recordações da casa dos Mortos, Dostoiévski conta comovido os atos de uns infelizes que se comportam como crianças grandes, se distraem com o teatro e brigam entre si com uma pueril falta de ira. Dostoiévski não se encontrou com o autêntico mundo do crime, nem chegou a conhecer. Diante deste mundo, Dostoiévski não se teria permitido expressar simpatia alguma ${ }^{3}$. (CHALÁMOV. 1959)

Pois em Kolimá as coisas eram bem diferentes:

São incontáveis as maldades dos ladrões nos campos. Suas desgraçadas vítimas são homens trabalhadores de quem o ladrão arranca o último trapo, furta o último dinheiro e a vítima não se atreve a queixar-se, pois vê que o ladrão é mais forte que a autoridade. O ladrão pega o trabalhador e o obriga a trabalhar; são dezenas de milhares os homens que os ladrões bateram até a morte. A ideologia do crime corrompeu centenas de milhares de seres que passaram pelo cárcere e que na prisão deixaram de ser homens ${ }^{4}$. (CHALÁMOV. 1959)

Para Chalámov, os criminosos não eram pessoas e ditavam o modo de vida na prisão. Estamos bem longe do caminho de regeneração de Dostoiévski: "O campo de trabalho é uma escola negativa da vida, negativa por inteiro em todos os sentidos. Ninguém tirará nunca do campo nada de útil (...)" 5 (CHALÁMOV. 1959) Diz

\footnotetext{
3 Достоевский в «ЗапискахизМертвогодома» которыеведутсебякакбольшиедети, ребяческибезгневноссорятсямеждусобой. незналлюдейизнастоящегоблатногомира. ЭтомумируДостоевскийнепозволилбывысказатьникакогосочувствия.

4 Неисчислимызлодеянияворов в лагере. Несчастныелюди - работяги, у которыхворзабираетпоследнюютряпку, отнимаетпоследниеденьги, и работягабоитсяпожаловаться, ибовидит, чтоворсильнееначальства. Работягубьетвор и заставляетегоработать десяткитысячлюдейзабитывораминасмерть. Сотнитысячлюдей, побывавших в заключении, растленыворовскойидеологией и пересталибытьлюдьми.

$5^{5}$ Лагерь - отрицательнаяшколажизницеликом и полностью. Ничегополезного, нужногониктооттуданевынесет (...)
} 
aindaChalámov: "Tantas são ali as coisas que o homem não deve saber, que não deve ver, e se tiver visto, mais vale morrer."6

\section{Trabalho, salvação e morte}

O trabalho é um tema fundamental nos dois autores: em Kolimá, ele mata, em Omsk, salva. Dostoiévskiconsiderava o trabalho ao ar livre, ainda que trabalho forçado,como salutar e desejável, achava que o trabalho aliviava as tensões, os homens viveriam brigando se não fossem obrigados a trabalhar:

No que me dizia respeito, eu percebia que só o trabalho me salvaria, resguardando minha saúde e meu corpo das influências de um pessimismo destrutivo. A constante inquietação espiritual, a provação dos nervos, o ar viciado dos alojamentos acabariam comigo. Respirar ao ar livre, todos os dias; trabalhar até o esgotamento; carregar pesos: fazer isso, pensava eu, pelo menos movido pela vontade e necessidade, possibilitará que meu corpo não se atrofie, isso me dará saúde, vigor para não deixar um dia o presídio como um velho. (DOSTOIÉVSKI. 2006. P. 109)

O trabalho chega a ser agradável e a proporcionar alegria:

Outro trabalho de que eu também gostava muito era o de remover neve. (...) Aquela poeira de neve brilhava no ar e esse era o único trabalho feito pelos detentos com verdadeira alegria. $\mathrm{O}$ ar gelado e o movimento nos estimulavam; havia troca de risadas, gracejos, bate-papos. Jogávamos bolas de neve uns nos outros, e até os mais fechados acabavam se contagiando pela alegria imperante, apesar de muitas vezes tal alegria dar origem a brigas e diferenças. (DOSTOIÉVSKI. 2006. P. 112)

Chalámov escreveu um conto, “O Mulá tártaro e o ar livre”,interpretando a expressão "ar livre" de Dostoiévski à sua maneira, à maneira de seu tempo. O conto se passa em uma cela de prisão, onde Chalámov ouve um homem comentar que se lhe derem vinte anos na prisão ele aguenta, mas se lhe mandam a um campo, ou seja, ao "ar livre", poderia aguentar no máximo dez anos: "Hoje, enquanto relia Recordações da Casa dos Mortos, me lembrei daquele bravo e inteligente mulá. O mulá sabia o que era

\footnotetext{
${ }^{6}$ Таммноготакого, чегочеловекнедолжензнать, недолженвидеть, а есливидел - лучшеемуумереть.
} 
isso de 'ar livre'." (CHALÁMOV. 1955). Ao longo do conto, entendemos o que significava "ar livre" no campo stalinista:

Em um campo, em uma mina de ouro ao ar livre, com um saudável ar invernal, com uma jornada de 16 horas e sem feriados, com fome sistemática, uns farrapos como roupa, umas horas de sono a sessenta graus abaixo de zero, em uma barraca de lona furada, e recebendo surras dos encarregados, dos criminosos convertidos em capatazes e dos guardas, para que, nestas condições, um homem jovem saudável, que começa sua carreira, se converta em um "terminal", são necessários vinte a trinta dias. ${ }^{8}$ (CHALÁMOV. 1955)

Segundo Chalámov, oshomens que deixavam as prisões,com seu ar viciado, interrogatórios e tensão constante,sonhavam com o "ar livre" do campo de trabalho. Quando chegavam, encontravam a atmosfera rarefeita da taiga com seus vapores pantanosos. Os pés passavam todo o dia molhados e no inverno tudo se cobria de gelo. Os mosquitos cobriam o rosto todo, era impossível trabalhar sem proteção e impossível trabalhar com ela. Para um trabalho de 16 horas, descontando o tempo de comer, de se locomover até o local de trabalho, das contagens intermináveis, sobravam 4 horas de sono. Ódio: era esse o sentimento que o trabalho em Kolimá despertava (CHALÁMOV.1955). A situação era a tal ponto desumana, que nenhuma brigada chegava inteira ao final da temporada de verão, por exemplo, que ia de 15 de maio a 15 de setembro; em geral sobravam apenas o chefe e seus amigos: os homens morriam como moscas. Estamos bem longe da alegria descontraída e das brincadeiras na neve de Dostoiévski.

Além disso, as cotas eram impossíveis de serem atingidas. E Chalámov esteve em alguns campos que seguiam uma regra cruel: a comida estava condicionada à realização das cotas, ou seja, ficava sem comida a brigada de trabalho que não a atingisse. Os números são absurdos: a cota no tempo dos dezembristas (como ficaram conhecidos os participantes de uma revolta contra o czar em 1825)era de 3puds de terra, ou seja, cada trabalhador deveria mexer com trêspuds de terra no trabalho na mina. Isso

\footnotetext{
${ }^{7}$ Я вспомнилэтогободрого и умногомуллусегодня, когдаперечитывал «ЗапискиизМертвогодома». Муллазнал, чтотакое «чистыйвоздух».

8 В лагередлятого, чтобыздоровыймолодойчеловек, начавсвоюкарьеру в золотомзабоеначистомзимнемвоздухе, превратился в нуженсрокпоменьшеймереотдвадцатидотридцатиднейпришестнадцатичасовомрабочемдне, безвыходных, присистематическомголоде, рванойодежде и ночевке в шестидесятиградусныймороз в дырявойбрезентовойпалатке, побояхдесятников, старостизблатарей, конвоя.
} 
vinte e cinco anos antes de Dostoiévski ir para a prisão. No tempo de Chalámov, a cota era de oitocentospuds, sendo que cada pud equivale a 16, 38kg (DOMÍNGUEZ. 2007).

Havia o escorbuto generalizado, a disenteria, a pelagra, a extenuação e a distrofia alimentar, nome encontrado (e permitido) pelas autoridades para falar de um dos grandes males do campo: a fome. Os barracões úmidos, a impossibilidade de se esquentar, os congelamentos, a falta total de esperanças. $\mathrm{O}$ prisioneiro vivia apenas para o dia de hoje, impossível fazer planos para "amanhã". Para Chalámov, a esperança é uma maneira de destruir a vontade do homem, é um fantasma traiçoeiro que inocula a corrupção nas almas dos presos, como escreve em um de seus contos. Já Dostoiévski contava os dias que faltavam para o término da pena. Ele diz: "Comecei a sonhar com a liberdade desde o primeiro dia de reclusão" (DOSTOIÉVSKI. 2006. P. 108). A esperança, segundo ele, sustenta o prisioneiro: mesmo os que tinham uma pena muito longa, sempre sonhavam em sair dali, sonhavam com algum milagre, uma reviravolta do destino.

\section{O eterno caráter do homem}

E Chalámovconclui o conto "O mulá tártaro e o ar livre" e, ao mesmo tempo, a relação de sua obra com a de Dostoiévski:

Por isso, se falamos dos campos, não vale a pena polemizar com Dostoiévski sobre as vantagens do "trabalho" comparado com a vida ociosa dos cárceres, sobre as virtudes do "ar livre". Os tempos de Dostoiévski foram outros, e os trabalhos forçados de então não haviam alcançado os extremos sobre os quais temos falado aqui ${ }^{9}$ (CHALÁMOV. 1955).

Em um texto intitulado "Dostoiévski" (1970), Chalámov conta que lera Recordações da Casa dos Mortos em 1949, quando trabalhava como enfermeiro em Kolimá (cargo que ocupara em seus últimos anos de reclusão e que lhe permitira sobreviver a ela). E durante muito tempo acalentara o desejo de escrever um comentário expondo a ingenuidade do livro, seus clichês literários. Mas muda de ideia: percebe que ali há algo que é eterno e se lembra, por exemplo, da conclusão de Dostoiévski em Recordações da Casa dos Mortos segundo a qual o homem se acostuma a tudo.

\footnotetext{
9 Поэтомунетнуждыполемизировать с Достоевскимнасчетпреимущества «работы» накаторгепосравнению с тюремнымбездельем и достоинствами «чистоговоздуха». ВремяДостоевскогобылодругимвременем, и каторгатогдашняяещенедошладотехвысот, о которыхздесьрассказано.
} 
Concorda com isso, embora achasse que o romancista não sabia até que limites de sofrimento poderia o homem se acostumar. MasKolimá não era a Casa dos Mortos, Kolimá era um campo de extermínio, como disse Chalámov. Mesmo com experiências diferentes, épocas diversas, conclusões opostas a respeito de suas detenções, Chalámov e Dostoiévski compartilhama busca pelo homem, ainda que no detento mais destruído, onde não se pensaria encontrar um ser humano. SegundoChalámov _ e podemos dizer dizer a mesma coisa sobre Dostoiévski_o que fica, provavelmente, é o eterno caráter do homem.

\section{Referências Bibliográficas}

Applebaum, Anne. Gulag, Historia de los campos de concentración soviéticos. Barcelona: Debolsillo, 2006

Chalámov, Varlam. O prose (Sobre a prosa). 1965. Disponível em http://www.shalamov.ru/library/21/45.html.

. "Dostoiévski". 1970. Disponível em http://www.shalamov.ru/library/21/53.html

. "KrasniKriest" (Cruz vermelha). 1959. Disponível em

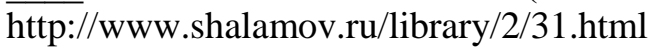

. "Tatarski mulá e chistievazdu” (O mulá tártaro e o ar livre). 1955. Disponível em

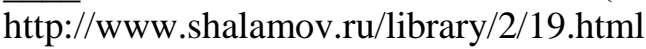

. O maiei prose (Sobre a minha prosa). 1971. Disponível em

http://www.shalamov.ru/library/21/61.html

Domínguez, Carlos Espinosa. "El poeta delinfierno congelado". In:Renacimiento.

No55/58. 2007 (pp 141-152), Jstor

Dostoiévski, Fiódor. Recordações da Casa dos Mortos. São Paulo: Nova Alexandria. 2006

Frank, Joseph. Dostoiévski, os anos de provação. São Paulo: Edusp. 1999

Toker, Leona. "Samizdat and the problem of authorial control: the case of

VarlamShalamov". In: Poetics Today (2008) 29(4): 735-758

http://poeticstoday.dukejournals.org/content/29/4/735.full.pdf+html 